\title{
La trayectoria de los monasterios cistercienses del sudoeste gallego desde la congregación de Castilla
}

\author{
María SeiJAs MonTero \\ Universidad de Vigo \\ mariaseijas@uvigo.es
}

Recibido: 27 de agosto de 2010

Aceptado: 22 de junio de 2012

\section{RESUMEN}

En este trabajo se analiza la trayectoria de los monasterios cistercienses de Galicia, especialmente los situados en la actual provincia de Pontevedra, desde su integración en la congregación de Castilla. Una unión que no supuso por sí sola un cambio radical de los monasterios, pero marcó el inicio de la modernización. La dinámica de esta nueva etapa va a estar marcada por unas directrices que permanecen inalterables hasta la exclaustración: mantener el patrimonio adquirido, mejorar su administración y defender los derechos de los respectivos monasterios, gravemente lesionados por la dejadez y mala administración de tiempos pasados.

Palabras clave: Galicia, cistercienses, congregación de Castilla, modernización.

\section{The Southwest Cistercian monasteries of Galicia since their integration into the congregation of Castile}

\begin{abstract}
In this paper we analyze the history of the Cistercian monasteries of Galicia, especially those in the present province of Pontevedra, since their integration in the congregation of Castile. The union itself did not change dramatically the monasteries, but it marked the beginning of modernization. The dynamics of this new period will be marked by guidelines that remained unchanged until the secularization: that is, to maintain the patrimony, to improve administration and to defend the rights of the monasteries, severely injured by the carelessness and mismanagement in the past.
\end{abstract}

Key words: Galicia, Cistercians, congregation of Castile, modernization. 


\section{PROCESO DE INTEGRACIÓN DE LOS MONASTERIOS}

Las órdenes religiosas en la España Moderna se ven inmersas en el proceso general que experimenta la iglesia española en esos siglos, especialmente en los inicios de la modernidad cuando afloran las tendencias de purificación y mejora nacidas contra la relajación existente en los tiempos finales de la Edad Media, unas tendencias canalizadas por los Reyes Católicos y Cisneros, cuya onda se prolonga hasta el concilio de Trento. Este deseo de reforma se puso de manifiesto en la aparición, ajuste y decisiva transformación de algunas órdenes religiosas. Sin embargo no todas reaccionaron de la misma forma, ni sufrieron con igual intensidad dicho proceso de renovación. Pese a diferencias y coincidencias en la exigencia reformista, en el ámbito de la vida religiosa la mayoría reaccionó con la formación de una congregación de observancia que se inclinaba por potenciar la interioridad del individuo a través de la oración y de la mortificación con el apoyo de la vida en comunidad y que reunía a los monasterios y conventos que deseaban la vuelta al estricto cumplimiento de su regla primitiva ${ }^{1}$. Por lo que se refiere a los monasterios cistercienses de los que se ocupa este estudio, la reforma se origina en la primera mitad del siglo XV en el monasterio aragonés de Santa María de Piedra por obra de fray Martín de Vargas, maestro universitario que se decidió a emprender una auténtica restauración del Císter, inspirándose principalmente en su primitiva forma de vida. Consiguió la autorización papal el 24 de octubre de 1425 por la bula Pia supplicum vota de Martín V e inició la nueva observancia en el monasterio de Montesión, en las inmediaciones de Toledo, que fue la verdadera casa madre y cuna de la nueva observancia ${ }^{2}$. Tras él surgieron otros centros como el de Palazuelos (Valladolid), casa central de reformadores y de los capítulos genera$\mathrm{les}^{3}$, a los que siguieron otros que llevaron a fijar definitivamente la estructura de la nueva familia cisterciense, sancionada por la bula Ad decoren del 25 de noviembre de $1434^{4}$.

Con el reinado de los Reyes Católicos (1474-1516) se emprende una sistemática política de control de las instituciones que se extiende a los monasterios cistercienses mediante la obligada adscripción a la congregación de Castilla, y la dura oposición

1 Martínez Ruiz, E. (dir.): El peso de la Iglesia. Cuatro siglos de Órdenes Religiosas en España, Madrid, Editorial Actas, 2004, pp. 112-113.

2 "Vino pues (fray Martín de Vargas) al lugar donde ahora esta la ermita de Nuestra Señora de Monte Syón, que es en un repecho y cuesta, de donde están pendientes muchas peñas (lugar bien a propósito para las contemplaciones) y visto que era abundoso de aguas y fértil para poderse labrar una vega, que cae en la ladera del cerro, que llama la Vega de S. Román, y que esta cerca de las riberas del río Tajo, cuyo servicio no seria de poca importancia a los monges..." cfr. en Montalvo, B. de: Primera parte de la Crónica de la Orden de Císter e instituto de San Bernardo, Madrid, por Luis Sánchez, 1602, fol. 341.

3 "El capítulo general se ha de celebrar en el Monasterio de Palazuelos, o en otro qual los Definidores, y General señalaren: y no le señalando, es visto quedar señalado el dicho Monasterio de Palaçuelos para los capítulos generales, y intermedios". Definiciones de la S. Orden del Císter y Observancia de España, Valladolid, por Antonio Vázquez, 1637, f.1v., Rse 304, Biblioteca Universitaria de Santiago (BUS).

4 Sobre fray Martín Vargas véase YÁnez NeIRA, D.: "Los monasterios cistercienses gallegos en la reforma de Fray Martín de Vargas", en Valle Pérez, J. C. (ed.): El Monacato en Galicia durante la Edad Media: la Orden del Cister, Santiago, Fundación Alfredo Brañas, 1991, pp. 71-106 y García Oro, J. y Portela Silva, M. ' J.: Los monasterios de la corona de Castilla en el reinado de los Reyes Católicos, Santiago, El Eco Franciscano, 2004, pp. 108 y ss. 
de los abades comendatarios y de muchos monjes que no veían con buenos ojos que se les privase de acumular más propiedades ni volver a la observancia estricta de la orden. El camino no podía ser fácil ya que a la indecisión de las propias órdenes se unían las oscilaciones pontificias que apoyaban, por un lado, a las congregaciones de observancia y, por otro, favorecían a los religiosos mediante la concesión de privilegios. A pesar de esta situación a finales del siglo XV la Sagrada Congregación de San Bernardo y observancia de Castilla, o más popularmente, Orden de los bernardos, empieza a tomar forma ${ }^{5}$. ¿Y cuál era el estado real de los cenobios del sudoeste gallego en este momento? ${ }^{6}$ Seguramente como ha señalado García Oro conservasen sustancialmente el cuadro de vida regular tradicional aunque en ocasiones con cierto descuido y olvido de las tradiciones propias de la orden, con las trascendentales dificultades relativas a enajenaciones fraudulentas de bienes monásticos, privilegios y exenciones de la vida común, caprichos en la indumentaria monjil y, en fin, una serie de problemas que le llevan a perder el peso decisivo que antes del último cuarto del siglo XV habían tenido en la vida gallega medieval ${ }^{7}$. Los datos de García Oro permiten aproximarse a la población monástica existente en tres de los cuatros monasterios estudiados en este trabajo a través del número de otorgantes que aparecen en los documentos. Así, a principios del siglo XV, concretamente en 1402, el monasterio de Oia contaba con 13 monjes $^{8}$, Armenteira con 12 en $1420^{9}$ y 6 en $1498^{10}$; en A Franqueira se registran tres otorgantes en $1496^{11} \mathrm{y}$ otros tres en $1506^{12}$. Comunidades pequeñas que, sin embargo, avanzaron con firmeza en el nuevo proceso de la reforma en los inquietos tiempos en que se inaugura la modernidad.

¿Y cómo se lleva a cabo la iniciativa reformadora en Galicia? Existe una fecha en principio clave, aunque no obtiene los resultados deseados, la de 11 de diciembre de 1487 en la que la concesión de la bula Quanta in Dei Ecclesia expedida por Inocencio VIII autoriza la corrección de los monasterios y su unión a la congregación castellana; en el mismo año de 1487 la bula Inter curas multiplices ordena la liberación de

5 Remitimos a Martín, E.: Los bernardos españoles. Historia de la Congregación de Castilla, Palencia, Gráficas Aguado, 1953.

6 Los monasterios cistercienses de los que se ocupa este estudio, y que se sitúan en la actual provincia de Pontevedra, son los masculinos de Aciveiro, Armenteira, A Franqueira y Oia (mapa 1). Vid. SeiJAs Montero, M.: Los monasterios cistercienses en el sudoeste gallego a fines del Antiguo Régimen, Santiago, Universidade de Santiago, 2010.

7 García Oro, J.: Galicia en los siglos XIV y XV, A Coruña, Fundación Pedro Barrié de la Maza, 1987 , pp. 441-445.

8 Fr. Gonzalo da Silva, abad; Fr. Alfonso, prior; Fr. Vasco, subprior; Fr. Estevo, celareiro; Fr. Gonzalo, maestre de vestiararía; Fr. Juan de Alenquer; Fr. Diego Durán, Fr. Acenso; Fr. Juan Alfonso, Fr. Juan Olvón, Fr. Juan Tamargo y Fr. Vasco. Archivo Histórico Nacional (AHN). 1839/8, cfr. en García Oro y Portela Silva, op. cit. (n. 4), p. 115.

9 AHN. 1776/21, cfr. en Ibidem, p. 115.

10 Fr. Gonzalo de Saavedra, abad; Fr. Rodrigo de Maceira; Fr. Juan de Aveancos, Fr. Álvaro Enano, Fr. Basco de San Vicenio y Fr. García de Piñeiro. AHN. 1479/9, cfr. en Ibidem, p. 115.

11 Don Alvaro de Paradela, abad; Fr. Vasco, prior; Fr. Juan de Barrantes "con todos los otros monjes do dito mosteiro", AHN. 1479/6, cfr. en Ibidem, p. 115.

12 Fr. Vasco de Freixo, abad; Fr. Joan de Barrantes, prior, Fr. Álvaro Colmeiro. AHN. 1786/5, cfr. en Ibidem, p. 115. 
los beneficios eclesiásticos de los seglares que los ocupaban ${ }^{13}$. Un año más tarde los reyes consiguieron del pontífice Alejandro VI la bula Apostolicae Sedis Providencia en la que permitían que el obispo de Catania, Diego Carrillo de Albornoz, emprendiese la reforma de las órdenes monásticas en Galicia, pero tampoco este consiguió sus objetivos por lo que delegó la empresa en los religiosos reformador de las respectivas órdenes. Y en 1494 el propio Alejandro VI encomienda la ejecución de la bula Quanta in Dei Ecclesia al abad de Poblet que fue sustituido por el Reformador de la observancia del císter en virtud del breve Carissimus de Julio II. A pesar de estas variaciones a finales del siglo XV comienza un nuevo período monacal en Galicia en el que los generales reformadores trabajan en la reforma con el apoyo dinámico del los Reyes Católicos. El primer monasterio en abrazar la observancia fue Santa María de Sobrado en los últimos años del siglo XV. Con la llegada del siglo XVI fue Santa María de Aciveiro la que se adhiere a la observancia en 1505, anexionándose al colegio de San Salvador de Salamanca en 1517. La anexión provocó la pérdida de la dignidad abacial por parte del monasterio -recuperada nuevamente bien entrado el siglo XVIII-, la sustitución de los abades perpetuos por los trienales, pero también la recuperación de la vida espiritual y conventual así como de la hacienda monásti$\mathrm{ca}^{14}$. Junto con Aciveiro se unen a la congregación de Castilla en los primeros años del XVI los monasterios de Penamaior, Monfero, Melón y Meira. De esta forma con los Reyes Católicos se dieron los primeros pasos en la búsqueda del nuevo modelo de monasterio grande, disciplinado y con fuerza económica, no obstante, el empuje definitivo de la Observancia llega con su nieto el emperador Carlos V que consigue estructurar y consolidar con firmeza, aunque también con inconvenientes, la reforma cisterciense.

\section{EL IMPULSO REFORMADOR DE CARLOS I}

El nuevo soberano Carlos I (1516-1556) era consciente de que la reforma iniciada por sus abuelos debía, en lo posible, mantenerse ${ }^{15}$. Siguió las pautas de centralización y burocratización iniciadas por ellos, gestionó las sanciones pontificias ante la curia romana y dirigió sus actuaciones desde la corte. Además, durante su reinado dio un gran protagonismo al futuro reformador general D. Juan Pardo de Tavera que era

13 García Oro, J.: Cisneros y la reforma del clero español en tiempos de los Reyes Católicos, Madrid, Consejo Superior de Investigaciones Científicas. Instituto Jerónimo Zurita, 1971, pp. $42-43$ y del mismo autor "La reforma de las órdenes religiosas en los siglos XV y XVI", en GonZÁlez Novalín, J. L. (dir.): Historia de la Iglesia en España, Tomo III-1 ${ }^{\circ}$, Madrid, Biblioteca de Autores Cristianos, 1980, pp. 211-350.

14 YÁnez Neira, op. cit. (n.4), pp. 102-103; Fernández Cortizo, C. X.: "Santa María de Acibeiro", en Yáñez neira, D. (coord.): Monasticón Cisterciense Gallego, vol. II, Vigo, Caixa Vigo e Ourense, 2000, p.160; García Oro, J. y Portela Silva, M. J.: "El císter gallego en el reinado de Carlos V" en García Oro, J. y Portela Silva, M. ${ }^{a}$ J.: Aproximación al reinado de Carlos V, A Coruña, Fundación Caixa Galicia, 2002, p. 21.

15 Una Cédula Real del emperador refiere en este sentido que "todas las casas de las dichas órdenes sean reformadas e visytadas conforme a las bulas que sobre ello fueron concedidas por los sumos pontífices pasados a suplicaçión de los católicos rey don Fernando e reyna doña Ysabel mis señores abuelos de gloriosa memoria e que las causas que tocaren a la dicha reformaçión e a todas las casas de las dichas ordenes sean muy miradas y favorecidas por ser como son fundadas e dotadas por los reyes nuestros predecesores", Sección Clero, Sign. 266-13, Archivo Histórico Provincial de Valladolid. 
cardenal-arzobispo de Santiago y presidente del Consejo Real, pero sus múltiples ocupaciones llevaron al emperador a sustituirlo por el obispo de Badajoz, D. Jerónimo Suárez, que se dedicó sobre todo a actuar como juez arbitrio en las querellas que surgían en la reforma monástica. Gracias a estas iniciativas del proyecto carolino la observancia cisterciense vive su etapa más importante, logrando reajustar la vida interna de la congregación y consolidando la reforma ${ }^{16}$; sin embargo, el camino no fue fácil, muchos eran los inconvenientes y las agitaciones a los que tuvo que enfrentarse el emperador. Uno de los que más le preocupaba era la resistencia que oponían los abades comendatarios lo que le llevó a obtener a través de su embajador documentos pontificios que permitiesen anular los títulos de encomiendas a los particulares. No menos importante fue el apoyo real a los proyectos de la observancia, como demuestran las gestiones que en 1522 hace su embajador, D. Juan Manuel, para procurar de la Curia la confirmación de las reformas ya realizadas y, por consiguiente, la continuación eficaz de la difusión de la observancia cisterciense. Serias disputas y apoyo decidido de la corte de Carlos I las hubo también en relación al gobierno trienal de los abades que fue tachado de secesionista por el capítulo general de la orden lo que le lleva a crear en 1524 una comisión para promover un pleito ante la curia. También dentro de la propia congregación la rotación trienal era causa de importantes disputas, por lo que en el capítulo celebrado en el monasterio de Montesino de 1525 se decidió recurrir a la corte para que solicitase la definitiva sanción pontificia. Lo que lleva a cabo el soberano mediante su embajador, el duque de Sessa, en 1526. Finalmente, y luego de superados los obstáculos la reforma cisterciense logra consolidarse en la época de Carlos $\mathrm{V}^{17}$.

¿Y cuál es la situación de los cenobios gallegos durante los primeros años del emperador? De los trece existentes en 1517 quedaban todavía Montederramo, A Franqueira, Armenteira, San Clodio, Oseira, Xunqueira de Espadañedo y Oia por aceptar la reforma. La mayoría continuaban enzarzados en un sistema beneficial, con monjes claustrales que procedían autónomamente en la parcela de la administración que les correspondía y con abades comendatarios protagonistas de numerosos pleitos con los reformadores generales en su afán de no perder sus privilegios ${ }^{18}$. Precisamente en 1566 el licenciado fray Benito de la Peña se refería a los abades comendatarios relatando que:

El daño que podía venir a la orden de tener posesiones y riquezas pues fueron puerta y causa de casi perderse esta orden y aun hoy no esta del todo recobrada la perdida y

\footnotetext{
16 "Se consolida la reforma en los claustros castellanos de Huerta, Ovila, Matallana, Rioseco, Monsalud, San Pedro de Gumiel. Más difíciles fueron las cosas en los de San Marcos de Castañeda en León, Nogales y Belmonte en Asturias y Osera, Oia, Armenteira, San Clodio y Montederramo en Galicia", cfr en Martínez RUIZ, (dir.), op. cit. (n. 1) p. 134, n. 3.

17 García Oro, José: "La reforma del Císter gallego en el reinado de Carlos V", Estudios Mindonienses, 7, (1991), pp. 659-673; Fernández Cortizo, C. X.: "Las reformas de las Órdenes de San Benito y del Cister en Galicia en tiempos de Carlos V", en Eiras Roel, A. (coord.): El reino de Galicia en la época del emperador Carlos V, Santiago, Xunta de Galicia, 2000, pp. 847-877.

18 García Oro, J. y Portela Silva, M. ${ }^{\mathrm{a}}$ J.: Los monasterios de la corona de Castilla en el reinado de Carlos $V$ ¿La Reforma o la Institución?, Santiago, El Eco Franciscano, 2001, p. 110 y "La monarquía y los monasterios gallegos en el siglo XVI. La hora de la recuperación”, Estudios mindonienses, 24 (2008), pp. 13-304.
} 
daño fue pues ansí q como cada uno de los monasterios desta orden tuviese grandes riquezas y posesiones y rentas muchas personas ansí eclesiásticas como seglares, impetraron muchos monasterios y abadías para los tener en encomienda, y los comendadores de ellas ponían un sustituto seglar o monje, que cobraba la renta y no curaba del oficio divino ni guarda de religión, ni de la sustentación de los monjes, como pastor mercenario (...) no solamente en este tiempo recibió esta orden este daño mas aun ansimesmo muchos obispos y oficiales apostólicos pretendieron usurpar la jurisdicción de los dichos monasterios y monjes de ellos (...) Y como sea ansí, que de un inconveniente se sigue otro, según el legislador dice, desto se siguió que muchos monjes se levantaron con gran libertad y andaban vagabundos (...) que visitas y correciones no podían hacerse en los monasterios porque luego amenazaban los monjes a los abades ${ }^{19}$.

En esta tesitura no puede resultar extraño el interés por la consolidación de la reforma en Galicia cuyo impulsor fue el reformador general fray Lorenzo de Peñafiel que clamaba desde 1515 por la recuperación de la familia cisterciense haciendo hincapié en la importancia de que se sintiesen bien aquellos que venían destinados a Galicia desde tierras castellanas, pues no podían sufrir la falta de pan de trigo "e con esto no hay religioso que alla vaya destas partes, e los que van enferman luego con el pan de centeno que comen, y mueren, de manera que donde podría aver treynta religiosos, no ay diez". Insistía en la necesidad de traer trigo desde Andalucía ${ }^{20}$. Precisamente de este reformador salieron los primeros intentos de reforma en las abadías de Monfero, Montederrano, San Clodio y la pontevedresa de A Franqueira, que datan de 1517. Esta última se incorpora a la congregación de Castilla en 1521 por medio de una bula de León X, uniéndose al colegio de San Salvador de Salamanca tras haber renunciado a su abadía su abad comendatario D. Alfonso de Pisa ${ }^{21}$. El monasterio deja así de ser abadía aunque "para celebrar el culto divino, debía permanecer un monje de la Orden llamado Prior, nombrado o cesado a voluntad del Reformador" 22 . Verdaderamente, las reformas monásticas que se produjeron en Galicia en el tránsito del siglo XV al XVI no dejaron bien parada a la diócesis tudense por cuanto de las 13 abadías cistercienses existentes en Galicia en dicha época solo tres -pequeñas además- se encontraban en Tui: Melón, Oia y A Franqueira, aunque este último tendrá prácticamente durante toda la Edad Moderna la categoría no de monasterio, sino de presidencia, nombre con el que eran conocidas en dicha congregación las casas de menor entidad como lo demuestra los escasos seis monjes con los que contaba a finales del siglo XVI ${ }^{23}$. El presidente de dicha institución era nombrado, al igual que ocurría con los abades, en el capítulo general y a pesar de no tener tal categoría de abad disfrutaba de los mismos privilegios que ellos.

\footnotetext{
19 PEÑA, B. de la: Tratado de Origen de la Orden del Císter y reformación que de ella se hizo en estos reinos de Castilla, Ms. 855, Biblioteca Nacional de Madrid.

20 García Oro y Portela Silva, op. cit. (n. 14), p. 15.

21 Cédula real de Valladolid, 21 de noviembre de 1522, Archivo General de Simancas (AGS), Cédulas de la Cámara, lib. 61, fol. 214r.

22 Cfr. en Limia Gardón, F. X.: “Santa María de Oia”, en Yáñez neira, op. cit. (n. 14), p. 277.

23 Rey Castelao, O.: "La diócesis de Tuy en la época moderna" en García Oro, José (coord.): Historia de las diócesis españolas: Santiago, Tuy-Vigo, Madrid, Biblioteca de Autores Cristianos, 2002, volumen XIV, pp. 629 y ss.
} 
Dos años después del de A Franqueira conseguía la unión definitiva a la observancia el monasterio de Santa María de Armenteira que un año antes, en 1522, denuncia ante el Consejo Real su delicada situación por la ruina tanto de los edificios como de su economía fruto de las malversaciones que estaban realizando el abad comendatario y sus familiares. La incorporación del cenobio fue problemática en tanto en cuanto al reformador del Císter, Fr. Ignacio de Collantes, no le resultaron fáciles los tratos con el abad de Armenteira que renuncia a la abadía a favor de la congregación en 1523, luego de ser presionado y consiguiendo para él una compensación vitalicia como fue la de percibir la mitad de los frutos de la abadía. A pesar de esta renuncia la bula de la unión se retrasó hasta 1536 como relata el autor anónimo del Tumbo del monasterio "trece años que tardó el despacho de las bulas fue por controversias que hubo en el modo de la Renunciación por las condiciones que pedía Fr. Gonzalo de Saavedra". Luego de alcanzado el acuerdo la congregación "puso por presidente al padre Fr. Sebastián de Burgos que lo fue desde el fin del sobre dicho año de 1523 hasta el de 1526, que en su lugar fue puesto y nombrado por presidente Fr. Diego Hidalgo (...) y lo fue hasta el de 1528 que, por haber muerto dos meses atrás, el Abad don Fr. Gonzalo (...) le eligieron por su Abad (...) hasta 1543"24. A partir de este año fue elegido como abad de Monfero y sustituido por fray Antonio de Atienza que inicia el gobierno de los abades trienales en un momento en el que el monasterio de O Salnés había consolidado la recuperación del patrimonio monástico, iniciada en los años veinte, descubriendo en buena parte el mapa de su señorío. Suyas eran las tierras situadas en el juzgado de A Lanzada, la Tierra del Salnés y otras poblaciones como Lantaño, Cangas, Toalla y un largo etcétera ${ }^{25}$.

La incorporación del monasterio de Santa María de Oia a la congregación de Castilla en 1547 supuso la conclusión del largo proceso de reforma de las órdenes monásticas en Galicia. El por qué de esta tardanza es explicada con elocuencia en el Tumbo pequeño del monasterio:

En la ejecución y práctica de esta legitima facultad hubo varios y grandes estorbos y embarazos que vencer en casi todos los monasterios, pero en los monasterios de Galicia fueron mayores, porque encastillados los abades y los monjes en sus monasterios no admitían en ellos visitas ni reforma, ni hacian aprecio alguno del Reformador. Por esta causa, el R. P. Fr. Ignacio de Collantes, que era reformador por los años de 1523, recurrió al dicho emperador Carlos V para que su Magestad se sirviese enviar una persona que de su real orden desencastillase dichos monasterios y los pusiese para hacer en ellos su visita y reformación ${ }^{26}$.

Sin lugar a dudas la mayor resistencia que tuvo que sortear el reformador fue la del abad perpetuo fray Gregorio Nieto que con la llegada del lcdo. Alonso Cisneros al monasterio, con el fin de implantar la tan anhelada reforma, huyó a Portugal. Tal

24 Duarte, B.: "Historia del Monasterio de Armenteira", Compostellanum, Vol. 6, Santiago, (1961), pp. $102-103$.

25 García Oro y Portela Silva, op. cit. (n. 14), pp. 20- 21; Fernández Cortizo, op. cit. (n. 17), p. 862; Tobío Cendón, R.: "Santa María de Armenteira", en YÁñez Neira, op. cit. (n. 14), pp. 154-195 y Yáñez NeIRA, op. cit. (n. 4).

26 Cfr. en Fernández Cortizo, op. cit. (n. 17), pp. 866-867. 
huída supuso en principio un respiro para la congregación que veía ahora la oportunidad idónea para desposeerlo de la abadía e inhabilitarlo perpetuamente. Su sustituto fue fray Lorenzo de Orozco, monje de la reforma. Con todo la lucha de fray Gregorio Nieto no termino ahí, desde su "exilio" portugués, en la granja de Silva, propiedad del monasterio y situada en el distrito de Valença do Miño, preparó su estrategia viajando incluso a Roma para defender sus derechos. Ante esta situación se buscó una intervención directa del emperador con el rey de Portugal y con el conde de Vilareal, en cuyo señorío se encontraba la granja de Silva. El objetivo no era otro que recuperar los bienes lusitanos, pero en 1528 la muerte de Nieto supuso una situación de alivio para la congregación que consideró que era el momento oportuno para cerrar el acceso a nuevos abades comendatarios. A pesar de todo Oia no consigue la oportuna bula pontificia hasta bien entrados los años cuarenta, momento en el cual otro abad comendatario, el clérigo hispalense D. Alfonso de Morán, renuncia a la abadía. Y no es hasta 1554 cuando se produce la unión efectiva del monasterio, luego del pleito de la observancia cisterciense con el clérigo tudense y abad del monasterio, D. Juan Sarmiento de Sotomayor, que vio como el Consejo Real desestimaba sus pretensiones ${ }^{27}$.

De lo dicho habrá de deducirse que la primera mitad del siglo XVI fue clave para estas abadías por cuanto se incorporaron a la observancia luego de una larga lucha entre los encomenderos, apegados a sus privilegios, y los reformadores que pretendían liberar a los monasterios de los abusos que aquellos cometían en su patrimonio y en sus rentas. De esta forma el largo y arduo proceso hacia la reforma en el seno de la familia cisterciense ya estaba concluido, a partir de aquí empieza una nueva etapa en la que se revitaliza la vida monacal, comienza un nuevo periodo de auge económico $\mathrm{y}$, en definitiva, aflora con fuerza una comunidad renovada.

\section{LA MODERNIZACIÓN DE LAS CASAS CISTERCIENSES}

La integración en la congregación de Castilla no supuso por sí sola un cambio radical de los monasterios cistercienses, pero marcó el inicio de la modernización. Eran los tiempos en los que Felipe II (1556-1598) suprime el conventualismo y afirma la observancia como única forma válida en la vida de todo el clero regular ${ }^{28}$. El

\footnotetext{
27 "Visto por los señores del consejo de sus majestades...dixeron que lo pedido por parte del dicho D. Juan no obo ni a lugar y que le mandaban y mandaron que no use de la presentación que tiene de su alteza a la dicha abadía en este proceso presentada ni de la collación e posesión que por virtud Della se hizo e tomo" cfr en $L a$ ejecutoria de la abadía de Oia contra D. Juan Sarmiento de Sotomayor dada por los señores del Consejo en Valladolid a 7 de febrero de 1554, AHN, L. 10214, fol. 265r-266v. Sobre esta cuestión Vid también CENDÓN Fernández, M.: "Santa María de Oia”, en Yáñez neira, op. cit. (n. 14), pp. 198-223; Fernández Cortizo, op. cit. (n. 17), pp. 866-867; YÁÑEZ NeIRA, op. cit. (n. 25), pp. 98-99.

28 Hecho que se lleva a cabo en órdenes mendicantes como la franciscana, véase García Oro, J.: Franciscanismo en la España Medieval, Madrid, Consejo Superior de Investigaciones Científicas, 1988; REY CAStelo, O. y Barreiro Mallón, B.: "El clero regular mendicante en Galicia. Evolución numérica, procedencia social y comportamientos de los franciscanos. Siglos XVI-XX", Archivo Ibero Americano, (1989), pp. 459 y ss; Rey Castelao, O.: A Galicia clásica e Barroca, Vigo, Galaxia, 1998, pp. 156-157; Fernández Terricabras, I.: "La reforma de las órdenes religiosas en tiempos de Felipe II. Aproximación cronológica" en BELENGUER Cebrià, E., (coord.): Felipe II y el Mediterráneo, vol. II, Madrid, Sociedad Estatal para la Conmemoración de los Centenarios de Felipe II y Carlos V, 1999, pp. 181-204.
} 
proyecto filipino consigue además en 1561, mediante la concesión de Pio IV, que los cistercienses españoles sean dirigidos por un comisario pontificio desligándose así de la jurisdicción del abad de Citeaux. Igualmente en este período se lleva a cabo la reconstrucción económica de las casas cisterciense, la restauración de la observancia de la regla y la intensificación de su vida cultural. Precisamente fue la recuperación de los monasterios lo que posibilitó el ligero incremento del número de monjes en las comunidades monásticas. En 1584 vivían en los claustros cistercienses gallegos 304 monjes que aumentan a 408 según los datos del censo de 1591, que debe ser tomado con cautela debido a los errores de denominación y ausencias. Excluyendo a Oia que contaba con 22 monjes en 1584, ocupando el quinto puesto de los monasterios masculinos, detrás de Oseira y Sobrado con 50, San Clodio con 30 y de Montederramo con 28, los restantes monasterios en los que se centra este estudio se encontraban entre los de menor número de miembros de todo el territorio gallego. Así Aciveiro que solo cuenta con tres monjes en 1584 tendrá ocho en 1591, Armenteira aumenta de ocho a quince y A Franqueira de tres a seis ${ }^{29}$. Estos datos llevan a subrayar que en el monasterio de Oia se encuentra en 1584 el 7.2\% del total de los monjes cistercienses gallegos. Por su parte Aciveiro y A Franqueira no alcanzan el 1\% del total y Armenteira el 2.6\%. En 1591 Aciveiro y A Franqueira superan tímidamente el 1\% y Armenteira reúne al 3.6\%.

Ligero incremento para los monasterios pontevedreses que no impidió que en la segunda mitad del siglo XVI se ampliasen sus edificios y se renovasen parte de sus instalaciones, proceso que prácticamente no se detuvo hasta bien entrado el siglo XIX. No se puede olvidar que durante el mandato de los abades comendatarios las casas cistercienses perdiendo la majestuosidad que habían tenido en el período medieval lo que llevó a que los primeros monjes observantes enviados por la congregación se encontraran con una situación ciertamente desoladora en la provincia pontevedresa.

¿Y cómo se lleva a cabo la reforma? En un primer momento se inició por la reconstrucción de las dependencias destinadas a la comunidad, como el claustro, la sala capitular, el refectorio, la cocina y el dormitorio que pasa de ser comunitario a individual teniendo cada monje su propia celda ${ }^{30}$. En Santa María de Armenteira, comienza en torno a 1575, durante el abadiato de Martín de Salinas, la construcción del claustro bajo renacentista edificado por Bartolomé de Hermosa que no se concluye hasta 1623, recibiendo los últimos retoques en 1677 según una inscripción que se encuentra en una de las bóvedas del ala de levante. La casa aciveirense acomete su remodelación también en la segunda mitad del siglo XVI, siendo abad fray Martín García del Pueyo. En 1588 firma un contrato con un maestro de cantería local para levantar el claustro procesional. En el mismo período se llevan a cabo las reformas de los espacios próximos al patio, -capítulo, refectorio, cocina-, la transformación del dormitorio comunal en celdas individuales y el comienzo de las obras en la fachada principal de la iglesia en la que posiblemente trabajó el cantero Juan de la Fuente. También en Oia la renovación arquitectónica dio sus frutos acometiendo en el últi-

29 Datos tomados de Rey Castelao, O.: "La Iglesia gallega en tiempos de Felipe II: la aplicación del Concilio de Trento", Martínez Millán, J.: Felipe II, 1527-1598, III, Madrid, Parteluz, 1998, p. 351.

30 Vila Jato, M. D.: "El renacimiento monástico" en Vila Jato, M. D. y García Iglesias, J. M.: Galicia en la época del renacimiento. Galicia/Arte, T. XII, A Coruña, Ed. Hércules, 1993, p. 167. 
mo tercio del siglo XVI la construcción del claustro, la sala capitular y el refectorio atribuidos al cantero Pedro do Campo y la sacristía del monasterio edificada por Bartolomé de la Hermosa hacia 1570 al que se le atribuye también la construcción del sotacoro de la iglesia ${ }^{31}$. En Santa María de A Fraqueira los datos son más efímeros por cuanto del complejo monástico de los montes de A Paradanta solo queda en pie el templo abacial. Nada queda de las otras estancias comunitarias y posiblemente pocas reformas tuvieron, dada la escasa entidad del cenobio, en los más de tres siglos que perteneció a la congregación de Castilla. Existen no obstante algunos recuerdos cistercienses como una composición heráldica situada en la reja que limita el espacio SO de la cabecera para sacristía, reja situada en la nave antiguamente y que tenía la función de separar la parroquia de los monjes y que hace alusión a la congregación de Castilla a la que perteneció el monasterio desde el siglo XVI ${ }^{32}$.

Luego de la decadencia sufrida por los monasterios en la Baja Edad Media, el siglo XVI supone el inicio de una nueva época de esplendor tanto en los edificios monacales como en el propio gobierno de las comunidades. Es el momento de la tan polémica sustitución de los abades perpetuos por los trienales. Estos son ahora designados en capítulo general buscándose así una mayor centralización que afectaba también a los propios habitantes de los claustros pues la mayoría de sus miembros van a ser ahora foráneos ${ }^{33}$. Además en tiempos de Felipe II la familia cisterciense lograr recuperar el protagonismo que había tenido en el período medieval tanto por su influencia social y religiosa como por el poderío económico que llegan a adquirir convirtiéndose en auténticas empresas conventuales durante el Antiguo Régimen. Situación que puede resultar sorprendente teniendo en cuenta que numéricamente el clero regular gallego a finales del siglo XVI era muy reducido: 1621 religiosos y religiosas frente a los 3.090 efectivos enrolados en el clero secular. Cifras que sin embargo llevan a los bernardos, junto con los benitos, a estar muy bien representados en Galicia por comparación al resto de la corona de Castilla. ${ }^{34}$

\section{LA FUNCIÓN RELIGIOSA Y LA “TITULARIDAD SEÑORIAL” DE LOS MONASTERIOS}

Las abadías cistercienses se encontraban en la segunda mitad del siglo XVI en una situación privilegiada no solo para actuar como centros religiosos sino también como titulares de señorío y grandes propietarios. La ocupación religiosa les permitía ejercer el derecho de patronazgo y presentación en distintas iglesias, en las que nombraban al párroco encargado de la misma. Esta titularidad tenía su origen en la época medieval,

\footnotetext{
31 Sobre el arte cisterciense véase entre otros ViLA JATO, M. D.: "La arquitectura de los monasterios cistercienses en Galicia durante el Renacimiento" en VAlle pérez, X. C y otros (dir.): Arte del Císter en Galicia y Portugal, A Coruña, Fundación Pedro Barrié de la Maza, 1998, pp. 184-230; GoY DIZ, A.: "La arquitectura monástica en la provincia de Pontevedra en la Edad Moderna" en Chamoso Lamas, M.: Pontevedra no obxectivo de Manuel Chamoso Lamas. As nosas raíces, Pontevedra, Deputación de Pontevedra, 1999, pp. 51-76.

32 Valle Pérez, X. C: Santa María de A Franqueira. Monasterio cisterciense, León, Edilesa, 2003, p. 15; Limia GARDÓn, op. cit. (n. 22), p. 289

33 Sobre el origen foráneo de los monjes véase Rey CASTELAO, op. cit. (n. 29), p. 352.

34 SaAvedra, P.: La Galicia del Antiguo Régimen: Economía y sociedad, A Coruña, Hércules, 1991, p. 389.
} 
y se completó mediante donaciones y compras en el período moderno. Un ejemplo lo tenemos en el cenobio aciveirense que reúne veinticuatro parroquias y seis anejos por los que percibía ingresos económicos, aunque no de elevada cuantía, como los aportados por el rector de San Lourenzo de Vilatuxe que entregaba al monasterio tres fanegas de centeno y una de mijo o el de Santa María de Graba con cuatro fanegas de centeno o mijo. También los monasterios de Santa María de Armenteira, con nueve feligresías, y Oia, con veintitrés, se beneficiaban de esta titularidad que en ocasiones adoptaba fórmulas indirectas por estar aforadas a cambio de una renta en especie y/o dinero. No menos importante fue la condición señorial de las órdenes monásticas que les permitía ejercer determinados poderes además de cobrar ciertas cargas a sus vasallos; dicho de otro modo, la incidencia del régimen señorial no dependía solo de dichas cargas, sino que los vasallos deben soportar la presencia de jueces y mayordomos encargados de la administración de justicia ${ }^{35}$.

A mediados del siglo XVI, los monasterios cistercienses gallegos, entre ellos Aciveiro, A Franqueira y Oia poseen señoríos con sus respectivos cotos y lugares jurisdiccionales. Más peculiar es el caso del monasterio de Armenteira como indica un informe del propio monasterio, del 14 de octubre de 1552, en el que se relata que el citado cenobio " tubo antiguamente por privilegios de los reyes pasados de gloriosa memoria ciertos cotos con su jurisdicción y los arzobispos pasados de Sanctiago como personas poderosas en este reino de Galicia se la an tomado quedandose este monasterio con titulo de señor de los cotos y en ninguno dellos tiene jurisdicción civil ni criminal ni derecho de ningún vasallaje porque los arzobispos pasados se la tomaron y la aforaron a un Gonzalo de Valladares para el y sus descendientes". ${ }^{36}$ Esta situación es confirmada a mediados del siglo XVI con el proceso entre "el Arzobispo de Santiago y Gonzalo Valladares, juez de tierra de Lanzada de la una parte y el abbad y combento del monasterio de Armentera sobre la jurisdicción civil y criminal del coto de Armentera" 37 .

En la memoria de los vasallos del monasterio de Santa María de A Franqueira el presidente de la institución relata el 12 de noviembre de 1552 "que tiene un coto que se llama Franquera el qual tiene beinte y ocho basallos y nuebe viudas (...) tiene el

35 Al fin y al cabo como muy bien ha dicho el profesor Eiras Roel refiriéndose al régimen señorial del siglo XVIII, que seguro no era muy alejado de lo que ocurría en el XVI, "los vasallos de señorío estaban sometidos a los poderes intermedios de los señores jurisdiccionales, que ejercían la justicia y otras muestras de autoridad sobre sus personas; y además de satisfacer todos los gravámenes fiscales y las demás cargas comunes de origen eclesiástico o concejil, venían obligados a una segunda fiscalidad en beneficio de los señores intermedios" en "El régimen señorial en Galicia a finales de la Edad Moderna: evaluación", Obradoiro de Historia Moderna, $\mathrm{n}^{\circ}$ 6, (1997), p. 8. Véase también SAAVEDRA, P.: "Régimen señorial y administración local en la Galicia de los siglos XVI-XVIII", en II Simposio da Historia da Administración, Santiago, Escola Galega de de Administración Pública, 1994, pp. 26-63.

36 Referencia tomada de la respuesta dada por el monasterio de Armenteira a una petición del príncipe Felipe, para llevar a efecto una bula de Julio III, en la que reclama información sobre los lugares y rentas jurisdiccionales de todos los monasterios de la Orden con objeto de desmembrar señoríos por valor de 500.000 ducados que se incorporarían a la corona, en Consejo y Junta de Hacienda, leg, 116, AGS. Parte del documento cfr en FAYA DíAz, M. a A.: "Jurisdicciones de los monasterios cistercienses gallegos a mediados del siglo XVI", en Actas Congreso Internacional sobre San Bernardo e o Císter en Galicia e Portugal, V. II, Ourense, Xunta de Galicia, 1992, pp. 290-291.

37 Serie jurisdiccional. Legajo 9. Archivo Histórico Diocesano de Santiago. 
dicho monasterio otro coto que se llama Huma en el cual tiene beinte y siete basallos y tres viudas" ${ }^{38}$, con su respectiva jurisdicción civil y criminal en ambos casos. El abad de Santa María de Oia, fray Lorenzo de Salamanca, en el informe mencionado da cuenta de que el monasterio "tiene un coto junto al dicho monasterio que se dize de Oya tiene ciento y sesenta y un vasallos todos pecheros y beinte viudas sobre los quales tiene la jurisdicción civil y criminal (...) tiene otro coto que se llama Panjón en el qual tiene beynte y quatro vasallos pecheros y un hidalgo y quatro viudas sobre los quales tiene la jurisdicción civil y criminal" ${ }^{39}$. Respecto al monasterio de Aciveiro los datos que presentan las averiguaciones, seis cotos y ciento catorce vasallos, deben ser necesariamente inferiores a los reales teniendo en cuenta la importancia del monasterio por aquel entonces. Tampoco aquí, del mismo modo que ocurría con el cenobio de Armenteira, tenía el monasterio la jurisdicción civil y criminal que era del arzobispo de Santiago como se declara en el informe: "este monasterio antiguamente solía estar en posesión de nombrar y tener merino (...) y estos vasallos acudían a su llamamiento (...) y dende veynte e quatro años a esta parte el arzobispo lo fue entrando todo por fuerza y lo manda" ${ }^{40}$. Con estos datos y teniendo en cuenta que la referida averiguación de 1552 informa de la existencia de 4.264 vasallos en la totalidad de los cenobios cistercienses gallegos se puede concluir, con las reservas necesarias, que a mediados del siglo XVI los monasterios objeto de este estudio, exceptuando Armenteira, tenían 391 vasallos, el 9.1\% del total de Galicia ${ }^{41}$.

En cuanto al cobro de derechos jurisdiccionales las averiguaciones informan de que los vasallos del monasterio aciveirense "son obligados a pagar al dicho monasterio cada uno dellos al tiempo y fin de sus muertes por bya de lutuosa la mejor pieza de quatro pies que tienen y poseen (...) boy o baca o cavallo o otra cosa semejante y todos los recueros que tienen rocines son obligados de traer al dicho monasterio en cada un año a su costa tres moyos de vyno de donde les fuere señalado (...) y no se las da por razón de ello otra cosa syno tan solamente dos çelemines de çebada palos rocines y ansy mysmo todos los que no tienen rocines van con sus bueys y carros a trabajar en las labores del monasterio todas las vezes que les hes mandado" ${ }^{42}$. El monasterio de A Franqueira recibe de los vasallos del coto de A Franqueira cada año seis o siete mil maravedís de penas y otros servicios y del coto de Huma dos o tres mil maravedís. Por su parte, Oia recibe de los vasallos de los cotos de Oia y Panjón 10.000 maravedís en concepto de martiniega y la luctuosa que es un buey o vaca a la muerte de cada vasallo.

Evidentemente no es fácil con estos datos medir la importancia que tuvo el señorío jurisdiccional de los cenobios cistercienses del sudoeste gallego en el siglo XVI, sobre todo a la hora de conocer el espacio geográfico en el que los monasterios ejercían su poder jurisdiccional. Los datos elaborados por A. Eiras ${ }^{43}$ sobre el régimen señorial gallego, aunque de finales del XVIII, en el que el señorío secular ocupa un destacado

\footnotetext{
38 Consejo y Junta de Hacienda, leg, 116, AGS.

39 Ibidem.

40 Ibidem., cfr. en FAYA Díaz, op. cit, (n. 36), p. 291.

41 El 4.9\% le corresponde al monasterio de Oia, el 2.6\% a Aciveiro y el 1.6\% a A Franqueira.

42 Consejo y Junta de Hacienda, leg, 116, AGS.

43 Eiras Roel, op. cit. (n. 35), pp.7-46
} 
primer puesto, permiten entrever, que a pesar de las modificaciones que se produjeron en el mapa jurisdiccional de la Galicia Moderna, el señorío monástico no pudo tener en el siglo XVI la importancia que algunos testimonios de la época le quisieron dar al afirmar "que la mayor parte de las jurisdicciones y haziendas deste Reyno, después de los prelados del, son de los monasterios benitos y bernados" 44 . De esta forma y exceptuando el monasterio de Oia, que es catalogado por el profesor Eiras Roel como uno de los principales titulares del señorío gallego en el siglo XVIII ${ }^{45}$, se deduce que los cenobios del sudoeste pontevedrés no destacaron en el siglo XVI ni por el número de vasallos ni por la extensión de sus señoríos. Además en este siglo se llevó a cabo una política de desmembraciones para paliar los apuros hacendísticos de la corona, que llevó a muchos monasterios a perder algunos de sus cotos, como le ocurre al monasterio de Oia con los de Parada y Barreiros, desmembrados por la corona en el último tercio del siglo ${ }^{46}$.

Lo que es indudable es que el poder que ejercen los monasterios en su calidad de señores jurisdiccionales también tenía cierta importancia en las pocas veces que existe coincidencia entre la jurisdicción y la propiedad territorial. Este binomio repercute de forma notable en el interés de los cenobios por salvaguardar sus intereses económicos en unos territorios en los que tienen asegurado el control de sus vasallos gracias a la prerrogativa de provisión de cargos, como jueces y escribanos, existentes dentro de su jurisdicción. Con lo dicho, no se pretende afirma que el dominio jurisdiccional camine siempre de la mano del dominio territorial, bien al contrario, como ha indicado A. Eiras "los monasterios gallegos de la Edad Moderna parecen ser más importantes por su propiedad en tierras sobre las que no poseen dominio jurisdiccional" ${ }^{47}$. Además las casas cistercienses son instituciones rentistas que tienen en el patrimonio territorial la mayor partida de ingresos frente a los que le reportan los derechos de señorío que en total aportan un pequeño porcentaje en el conjunto

44 Testimonio remitido al rey por el juez averiguador de Galicia, D. Francisco González de Carvajal. Consejo y Junta de Hacienda, leg. 132, AGS, cfr. en Fernández Cortizo, C. X.: "Los monasterios cistercienses gallegos en tiempos de Felipe II", en Fernández López, R. (coord.): Monasticum, Santiago, Editorial Lápices, 1999, p. 19. Probablemente como ha señalado A. EIRAS "el tópico del predominio del señorío eclesiástico en Galicia nació de la confusión entre dominio señorial y propiedad dominical”, en "El señorío gallego en cifras: nómina y ranking de los señores jurisdiccionales", Cuadernos de estudios gallegos, T. 38, n. 103, (1989), p. 119. El profesor EIRAs señala además que a mediados del XVIII los 19 monasterios benedictinos y cistercienses de Galicia ejercen el poder señorial sobre un total de 31.011 vasallos (vecinos cabeza de casa que pagan los derechos señoriales), extendiendo su señorío sobre $2.549 .54 \mathrm{Km}^{2}$, en EIRAS ROEL, op. cit. (n. 35), pp. 131-134.

45 El monasterio de Oia cuenta en el siglo XVIII con 1.344 vasallos y $68.20 \mathrm{Km}^{2}$ de territorio señorial, en Eiras RoEl, op. cit. (nota 44), p. 132. En el mismo artículo el monasterio de Aciveiro que ocupa el puesto 179 de los 206 titulares de señorío analizados por A. EIRAs tiene 38 vasallos y $4.20 \mathrm{Km}^{2}$ de territorio señorial, p. 134.

46 Sobre esto véanse los artículos ya citados de Fernández Cortizo, op. cit. (n. 44), pp. 11-43 y FayA Díaz, op. cit. (n. 36), pp. 289-308. El efecto que el proceso de desmembración llevado a cabo por Felipe II tuvo en otros monasterios gallegos, como el femenino de San Paio, puede verse en Burgo LóPez, M. ${ }^{a}$ C.: "El señorío monástico gallego en la Edad Moderna", Obradoiro de Historia Moderna, 1, (1992), pp. 99-121.

47 Eiras Roel, op. cit. (n. 44), p. 122. Esta cuestión también fue abordada por Rey Castelao, O. en "Los fundamentos de la iglesia en la España del período moderno: quiebras y conflictos de mantenimiento" en MARtínez Ruiz, E. y SuÁrez Grimón, V. (eds.): Iglesia y Sociedad en el Antiguo Régimen: III Reunión Científica, Asociación Española de Historia Moderna, vol. I, Las Palmas, Universidad de las Palmas de Gran Canaria, 1994, pp. 391-408. 
de ingresos. De ahí el interés de los monjes blancos por controlar un patrimonio que está prácticamente configurado en el siglo XVI, momento en el cual los monasterios gallegos en general, y los pontevedreses en particular, buscan la reorganización y afianzamiento de sus dominios territoriales a través principalmente de la elaboración de los apeos, como los realizados por A Franqueira en 1582, Armenteira en 1585 y Aciveiro en 1588, y la reivindicación de bienes, promovidas ante la Real Audiencia, con el fin de esclarecer y defender sus propiedades ${ }^{48}$. Y en este proceso de reconstrucción de los dominios monásticos jugó un papel determinante el contrato foral que se consolidó masivamente como sistema de explotación de gran parte de los bienes monásticos en el siglo XVI, permitiéndole obtener importantes rentas y convirtiéndose en el soporte básico de su economía durante toda la Edad Moderna.

\section{LAS ACCIONES JUDICIALES Y EL CONTROL DE LA PROPIEDAD}

El siglo XVII quiso ser el de la definitiva implantación de la reforma tridentina en las casas regulares; de dicho Concilio salió un decreto en 1563 que pretendía, entre otras cosas, que los religiosos viviesen según el modo de vida establecido en sus respectivas reglas. Pero la realidad era bien distinta, exceso de poder y propiedades versus relajación de los ideales ascéticos, principalmente en el caso gallego donde sus riquezas eran cuantiosas, en un momento en el que existían 60 casas de monjes blancos, todas ellas situadas al norte del Tajo.

Con esta perspectiva es lógico que los monasterios bernardos intentasen continuar en el seiscientos con una política próxima a la llevada a cabo en el siglo anterior: control jurisdiccional sobre sus territorios y afianzamiento de sus propiedades. Sin embargo, si por algo se caracteriza el siglo XVII en los cenobios gallegos en general y en los pontevedreses en particular, es por la dinámica de conflictividad que lleva a los monasterios, en muchas ocasiones, a luchar por la propiedad que habían adquirido en siglos anteriores, sin olvidar la conflictividad señorial de las cuestiones jurisdiccionales. Una litigiosidad a la que no es ajena la propia documentación monástica como se relata en el tumbo de Oia al afirmar que la inmensidad de pleitos tienen su origen en que "por nuestros pecados todos los más tratan de despojarnos y negarnos y llevarnos lo que con tan larga mano los primeros fundadores nos dexaron" ${ }^{49}$. En todo caso, estás acciones judiciales no se resuelven siempre a favor del monasterio como ocurre en el monasterio acivierense que ve como a principios del siglo XVII tiene que enfrentarse a la pérdida de la jurisdicción de los cotos y encomiendas de Aciveiro a favor de la dignidad arzobispal de Santiago. El pleito, luego de un largo proceso iniciado en el siglo XVI, se resuelve en la Real Chancillería de Valladolid declarándose:

pertenecer al dicho monasterio de Acebeiro la jurisdicción acumulativa en los cotos $\mathrm{y}$ encomiendas de Acebeiro sobre que ha sido y es este dicho pleito para que la usen y

48 Fernández Cortizo, op. cit. (n. 44), pp. 26-27. La actividad judicial de la Audiencia de Galicia es ampliamente tratada por REY CASTELAO en su libro Montes y política forestal en la Galicia del Antiguo Régimen, Santiago, Universidad de Santiago, 1995.

49 Tumbo de Oia, 1606, L: 10.223, AHN, fol. $1 \mathrm{r}$. 
ejerzan por sus alcaldes y merinos lo qual sea y se entienda tan solamente para efecto de cobrar de sus renteros y colonos el pan de renta y maravedís y demás cosas que se le debieren al dicho monasterio y no mas y en todos los demás casos y cosas que se ofrecieren en los dichos cotos y encomiendas declaramos pertenecer la jurisdicción civil y criminal a los juezes y merinos puestos por el dicho arzobispo y los sucesores en su divinidad arzobispal ${ }^{50}$.

Pero no solo por cuestiones jurisdiccionales pleitea el monasterio de tierra de Montes, otras demandas por aprovechamiento de montes, dehesas, etc, formaran parte del día al día del monasterio aciveirense. No menos litigante fue el monasterio de Armenteira por cuestiones tan heterogéneas como la iniciada en 1612 entre el monasterio y D. Álvaro de Mendoza por querer este enterrarse en la capilla mayor o la suscitada en 1680 contra un ministro de la jurisdicción de A Lanzada:

por haber entrado en la iglesia deste convento con bara alta de justicia dicho día en que se celebraba en ella la cofradía de Nra Señora del Rosario e deviéndolo de hacerlo por ser como hes jurisdicción privativa civil y criminal de dcho monasterio, a lo cual el abad del citado monasterio respondió que habiendo visto dicho ministro (...) con dicha bara alta de justicia en las manos dentro de la Iglesia de dicho Monasterio se la quitó de las manos como dueño y señor de dicha jurisdicción y la rompio y para que semejante delito sea castigado y se sirva de escarmiento ${ }^{51}$.

Esta continua conflictividad en aras de proteger su patrimonio llevó también a los monasterios a intentar esclarecer sus dominios a través de los apeos con intención de mantener unos bienes perdidos, en ocasiones, como relata fray Nicolás de Robles en el tumbo de A Franqueira, "por la poca diligencia que en esto han puesto los presidentes que a havido en este monasterio que (...) an dado ocasión a que algunos de los mas ricos se queden como se quedan con mucha hazienda sin pagarle della renta" 52 . Apeos como los hechos por el referido monasterio de A Franqueira en 1616 para el pleito contra los deudores de la feligresía de San Xurxo de Ribadetea:

que tienen entrado y ocupado los dichos bienes sin titulo ni causa alguna (...) y ansí mismo han dexado de pagar la renta y pensión por razón dello devida al dcho Monasterio por muchos años por lo cual han caído en comiso y perdido cualquier derecho que los dichos vienes pudieron tener en caso de que los poseyeran por títulos de fuero y aunque muchas veces por mi parte fueron requeridos que dexasen libres y desocupados los dichos bienes nunca lo han querido hacer sin pleito $^{53}$.

O también los realizados por el monasterio en 1632 de todos los bienes que tiene en el partido de Casteláns y de una casa sita en la villa de Ribadavia ${ }^{54}$. Del mismo

\footnotetext{
50 Serie Comunidades Religiosas. Legajo 15, AHDS.

51 Libro tercero de ejecutorias (1652-1680), L. 9.928, AHN.

52 Tumbo de A Franqueira, 1656, L: 10.037, fol. 7v, AHN.

53 Apeo de los bienes de Ribadetea, 1616, L: 10.041, fol. 1r, AHN.

54 Tumbo de A Franqueira, 1656,L: 10037, AHN, fols. 161r y 416r.
} 
modo el monasterio de Oia en aras de salvaguardar su dominio apeó en 1696 toda la hacienda de la feligresía de San Mamede de Pedornes.

Pero Oia no solo defendió sus propiedades, su situación en el mismo litoral marítimo, lo convirtió en un lugar idóneo para los asaltos de los enemigos, lo que hizo que fuera construido a manera de fortaleza, dotándolo de armamento y munición suficiente para defenderse de cualquier ataque. El propio abad gozaba de la categoría de general, con potestad de poder levantar tropas en la comarca, cada vez que divisaba un peligro inminente. La defensa de la costa queda patente en episodios como el acaecido en 1624, durante el abadiato de Gabriel de Moreda, en el que los monjes de Oia hundieron varias embarcaciones de piratas que venían persiguiendo a naves cristianas "murieron treinta y siete Turcos, salieron a nado nueve que los monges cautivaron en la rivera, donde asistían a la defensa" ${ }^{55}$. Un año después en 1625, según se relata en el tumbo del monasterio los monjes defendieron a tres naves cristianas de cinco navíos de moros "comenzaron a disparar desde la plaza de Armas del Monasterio algunos mosquetazos y un religioso que había sido soldado cargando una pieza con una sola libra de pólvora (...) con tan buena fortuna, que con la vala hecho al fondo la mejor nave de los moros los cuales viendo el suceso se hicieron a la bela y huyeron" ${ }^{56}$. Evidentemente, muchos de estos episodios son poco creíbles, no obstante la condición de baluarte defensivo que ostentó el monasterio de Oia durante toda la Edad Moderna queda fuera de dudas dada la abundante documentación existente sobre el armamento requerido por los monjes para la defensa de la ría.

\section{LOS EFECTOS DELAUGE ECONÓMICO DE LAS CASAS CISTERCIENSES}

En grandes líneas se puede señalar que con la llegada del XVIII las casas cistercienses pontevedresas se seguían manteniendo gracias a las rentas forales obtenidas por la cesión de unos patrimonios formados en los siglos centrales de la Edad Media y reorganizados durante los tiempos modernos. En efecto, el siglo de las Luces supuso para las comunidades bernardas una fase ventajosa de ganancias monetarias, favorecida por la comercialización de las rentas como consecuencia del alza de los precios agrarios; al mismo tiempo monarcas como Felipe $\mathrm{V}$ auspiciaron esta situación de privilegio mediante la confirmación de mercedes y donaciones de los reyes anteriores ${ }^{57}$.

55 "Relación de la Victoria que los Monges Bernardos de Nuestra Señora de Oya tuvieron de cinco navíos de Turcos, en 20 de Abril", Biblioteca Nacional de Madrid, Ms. 23.555, publicado en Galicia Diplomática, año IV, no $16-17,21$ y 28 de abril de 1889, pp. 126-128 y 132-133.

56 Cfr. en YÁñez NeIrA, D.: El Monasterio de Oya y sus Abades, Pontevedra, Diputación de Pontevedra, 1974, p.53.

57 Felipe $\mathrm{V}$ favoreció las posesiones monásticas, entre ellas las de Oia, para que "se le mantenga perpetuamente en la posesión goze y propiedad de todo lo que le pertenece (...) según en la forma que lo ha obtenido". También en el monasterio de Armenteira una Real Cédula de confirmación del mismo monarca señala que es su voluntad que "se mantenga a el abad y monges que por tiempo fuesen en el referido real monasterio de Santa María de Armentera en la perpetua propiedad y goze de los lugares, heredades, cotos, rentas, derechos y demás pertenencias (...) sin que por mí ni los señores reyes mis sucesores con ningún motivo pretesto ni causa se les inquiete ni pueda inquietar en su justa y legítima posesión". Escribanía Mayor de Rentas, Leg. 400, f. 124 y f. 126 . AGS. 
Pero no todo era paz dentro de las comunidades, en las primeras décadas del XVIII surgió en el seno de la congregación una importante crisis debida a la distribución de los cargos en las abadías, en las que no todos tenían el mismo poder; situación arrastrada ya desde el siglo XVII cuando en 1671 se promulgó la bula bipartita según la cual la congregación castellana quedaba dividida, a efectos electorales, en dos grandes circunscripciones: una configurada con las abadías de Galicia y Castilla la Vieja y otra con las de Asturias, Rioja y Castilla la Nueva. Una centralización electoral que provocó nuevos enfrentamientos entre las dos facciones lo que llevó al papa a promulgar, en octubre de 1710, una nueva bula tripartita, por la cual la congregación se divida en tres facciones: Galicia, Castilla la Vieja y las Naciones (que incluía a los cenobios de Asturias, Rioja y Castilla la Nueva). Sin embargo la división establecida en la tripartita no contentó a la facción de las Naciones que apelaron al rey para que no permitiese la ejecución de la bula, retenida finalmente hasta 1717; una de las razones que se alegaron para que se mandase retener el breve obtenido por los campesinos y gallegos era:

que lo havían logrado sin oposición, y sin ser oídos los Castellanos, porque su procurador se havía salido de Roma por marzo del año de 1710 en obediencia de la orden para que todos los vasallos de V.Mgd. lo executasen, haviéndose quedado el de los campesinos y gallegos en aquella Corte, y logrado la expedición del breve por octubre del mismo año ${ }^{58}$.

En la comunidad de Aciveiro las diferencias internas de las distintas naciones también existieron, notándose un predominio de los campesinos posiblemente por la procedencia del abad -tierra de Campos- y por el control que sobre este monasterio pueda tener el jefe de esta nación para la presentación de ciertas abadías y la elección de $\operatorname{cargos}^{59}$.

Evidentemente la situación no mejoraba, bien al contrario suscitó importantes protestas lo que llevó al nuncio papal a prohibir en 1733 la convocatoria del capítulo general; sin embargo este, siguiendo las órdenes reales, llegó a celebrarse. En 1735, dada la situación de enfrentamiento entre las diferentes facciones que impedía a los monasterios "vivir en aquella Religiosa, y humilde uniformidad a que están obligados por su estado (...) y en la quietud correspondiente a su profesión", Felipe V promulgó una Real Cédula en la que obligaba a los cistercienses a dar cuenta al consejo de Castilla cada vez que vacasen sus cargos abaciales que serían nombrados por el propio monarca.

En 1738 una nueva concordia -denominada cuatripartita- fue sancionada por Felipe V y Benedicto XIV y aceptada por los representantes de todos los grupos existentes en la orden. El objeto de la misma era garantizar un equilibrio de fuerzas dentro de la orden por lo que hubo una distribución con rentas homogéneas e igual número de cargos capitulares en las cuatro provincias artificiales en que se dividió la Con-

\footnotetext{
58 Gracia y Justicia, Leg. 645, s.f. AGS.

59 Fernández Cortizo, op. cit. (n. 14), p. 171.
} 
gregación: Campos, Castilla, Galicia y Las Naciones ${ }^{60}$. El monasterio de Oia quedó englobado dentro de la de Castilla y Armenteira dentro de la de Galicia. Dicha distribución no afectó a Aciveiro y A Franqueira que no aparecen integradas en ninguna de las cuatro provincias, pues, probablemente, la anexión de sus rentas al Colegio de Salamanca, propició un menor interés por su control. Se ponía fin así a "la continuada porfía con que han persistido tanto años en fomentar sus parciales aficiones, consumiendo en ello exorbitantes summas, en deservicio de Dios, y de V.M" ${ }^{\text {. }}$.

Pero en el Barroco no todo fueron desavenencias gracias sobre todo al auge económico de las casas cistercienses. Así si en la época del Renacimiento los criterios de austeridad se habían olvidado, ahora la majestuosidad de las abadías cistercienses competían en riqueza y exhuberancia decorativa. En Acivero entre 1748 y 1800 se renuevan prácticamente todas sus dependencias con un criterio funcional aunque la importancia de los canteros de tierra de Montes se pone de manifiesto en la cuidada estereotomía de su sillería; se trabajó en la fachada de la portería y en las dependencias del abad, así como en la zona de la cocina y se construyeron los edificios destinados a la explotación agraria. En Armenteira se levantó durante el abadiato de Fabián Fernández, concretamente en 1778, una torre campanario que sustituyó a la primitiva espadaña. También del último tercio del XVIII son la fachada del monasterio, en la que se aprecia un deseo de cierta monumentalidad diferente al de otros lugares en los que trabajan los maestros de obras rurales, y las dependencias del noviciado que se construyeron hacia el poniente. En A Franqueira con la reforma barroca se hizo desaparecer el ábside de la iglesia, posiblemente semicircular, al hacer la ampliación de la cabecera convirtiéndose esta en la nave central de un plan compuesto por tres naves. En lo que atañe al conjunto monacal de Oia fue objeto de una nueva fase constructiva en la que se realiza la fachada principal de la iglesia, además de una escalera en el crucero de la misma que fue utilizada por los monjes para acceder directamente desde sus celdas al templo, y la edificación de una torre campanario entre el brazo norte de la iglesia y la sacristía, construida en la segunda mitad de la centuria por Juan Lomba, maestro de obras de A Guarda ${ }^{62}$. Como es lógico, esta actividad constructiva no puede disociarse del contexto socioeconómico del momento, al fin y al cabo, no se puede olvidar que la iglesia gallega fue durante todo el Antiguo Régimen un es-

60 Cfr. en López García, J. M.: La transición del feudalismo al capitalismo en un señorío monástico castellano: el Abadengo de la Santa Espina (1147-1835), Valladolid, Junta de Castilla y León, 1990, pp. $398-399$.

61 Gracia y Justicia, Leg. 645, s.f. AGS. Existieron sin embargo manifiestos en contra de la cuatripartita "passamos a hacer igual demostración de la injusticia, y enorme lesión, que por ella se hace a los mas Monges de esta Religión, y a los naturales de los más Reynos, y Provincias de España. Este assumpto se hará manifiesto, justificando en primer lugar, que los naturales de Galicia y de la asserta Provincia de Campos, no tienen derecho alguno privativo, ni de preferencia a los Hábitos, y honorifico de esta Religión, à titulo de situación de Monasterios en sus Países; y por la misma razón, ni à la mitad de todo lo honorifico de ella, que contra Derecho pretenden adjudicarse perpetuamente por la pretensa quatripartición" en Gracia y Justicia, Leg. 645, f. 6. AGS.

62 Folgar de la Calle, M. a del C.: La arquitectura de los monasterios cistercienses en Galicia desde el Barroco hasta la desamortización” en VAlle Pérez, op. cit. (n. 31), p. 284; VAlle Pérez, op. cit. (n. 32), pp. 15 y ss.; Limia Gardón, op. cit. (n. 22), p. 285 y Pereira Morales, A. Mª .: "El monasterio de Santa María de Oia. Intervenciones arquitectónicas del siglo XVIII", Quintana, n 2, (2003), pp. 211-225. 
tamento privilegiado que detentaba la propiedad del $52 \%$ de las tierras cultivadas ${ }^{63}$. Contó además con una coyuntura favorable, arrastrada desde el siglo XVII gracias a la introducción y posterior desarrollo del cultivo del maíz ${ }^{64}$, lo que benefició a las órdenes religiosas por cuanto vieron aumentar sus rentas de forma considerable y por consiguiente pudieron modificar notablemente el conjunto arquitectónico de los monasterios.

Modificaciones de unas dependencias monásticas que van asociadas al importante peso económico que en el XVIII tenía el clero regular gallego, lo que no significa que el número de monjes fuese muy numeroso, especialmente en los cenobios pontevedreses. En 1753, época de formación del Catastro de Ensenada, el monasterio de Oia se componía de 20 religiosos de misas, 2 coristas, 1 novicio, 1 donado y 9 criados legos "que sirven al monasterio para diferentes cosas que en el se ofrecen"; en Armenteira hay 20 monjes de misa, incluso el abad, 6 colegiales y 5 novicios; en Aciveiro 9 monjes de los que 8 son sacerdotes y 1 lego; y en A Franqueira 4 individuos eclesiásticos incluso "el abad prior que les domina" ${ }^{6}$. En 1787 de los 445 monjes cistercienses existentes en Galicia, el 7,8\% pertenecía al monasterio de Oia, el $4.7 \%$ a Armenteira, el $4 \%$ a Aciveiro y tan solo el $0.8 \%$ al pequeño monasterio de A Franqueira; resultados muy alejados de grandes comunidades como las de Sobrado y Oseira que reunían el $41 \%$ de los cistercienses, pero que no esconden el crecimiento de los monasterios del sudoeste gallego -excepto A Franqueira- desde el siglo XVI al XVIII ${ }^{66}$. Un aumento que continúa a principios del siglo XIX en todos los monasterios: Oia contará con 40 hijos de filiación, aunque solo 26 residían en el monasterio, Armenteira 26, Aciveiro 20 y A Franqueira $5^{67}$.

A partir de este momento la historia de los cenobios pontevedreses va pareja a la de otros monasterios gallegos en los que las leyes desamortizadoras del XIX llevan a los religiosos a abandonar sus respectivas casas.

63 Rey Castelao, O.: "La Iglesia en el contexto de la sociedad gallega en el Antiguo Régimen”, en VÁzQuez Varela, J. M. y otros: O feito religioso na Historia de Galicia, Noia, Asociación Galega de Historiadores, 1993, pp. 71-96. La estructura social y económica de Galicia puede verse en la obra de SAAVEDRA, op. cit. (n. 34), 1992.

64 Sobre esta cuestión véase PÉrez García, J. M.: “Aproximación al estudio de la penetración del maíz en Galicia” en Eiras Roel, A. (ed.): La historia social de Galicia en sus fuentes de protocolos, Santiago, Universidad de Santiago, 1981, pp. 117-159.

65 Dirección General de Rentas, Catastro de Ensenada, leg. 247, fol. 84, AGS.

66 Oia pasa de los 22 monjes con los que contaba a finales del XVI a los 35 de 1787, Armenteira de 15 a 21, Aciveiro de 8 a 18 y A Franqueira desciende de 6 a 4. Rey CAStelao, op. cit. (n. 29), p. 351 y Censo de 1787 “Floridablanca", V. 4, Madrid, 1990, p. 3.629.

67 Fernández Martín, L.: "Estado espiritual y temporal de los Monasterios Bernardos de Galicia en vísperas de la Guerra de la Independencia. 1803”, Hispania Sacra, 89 (1992), pp. 393-411. 


\section{APÉNDICE}

Mapa 1: Localización de los monasterios cistercienses masculinos en la Provincia de Pontevedra.

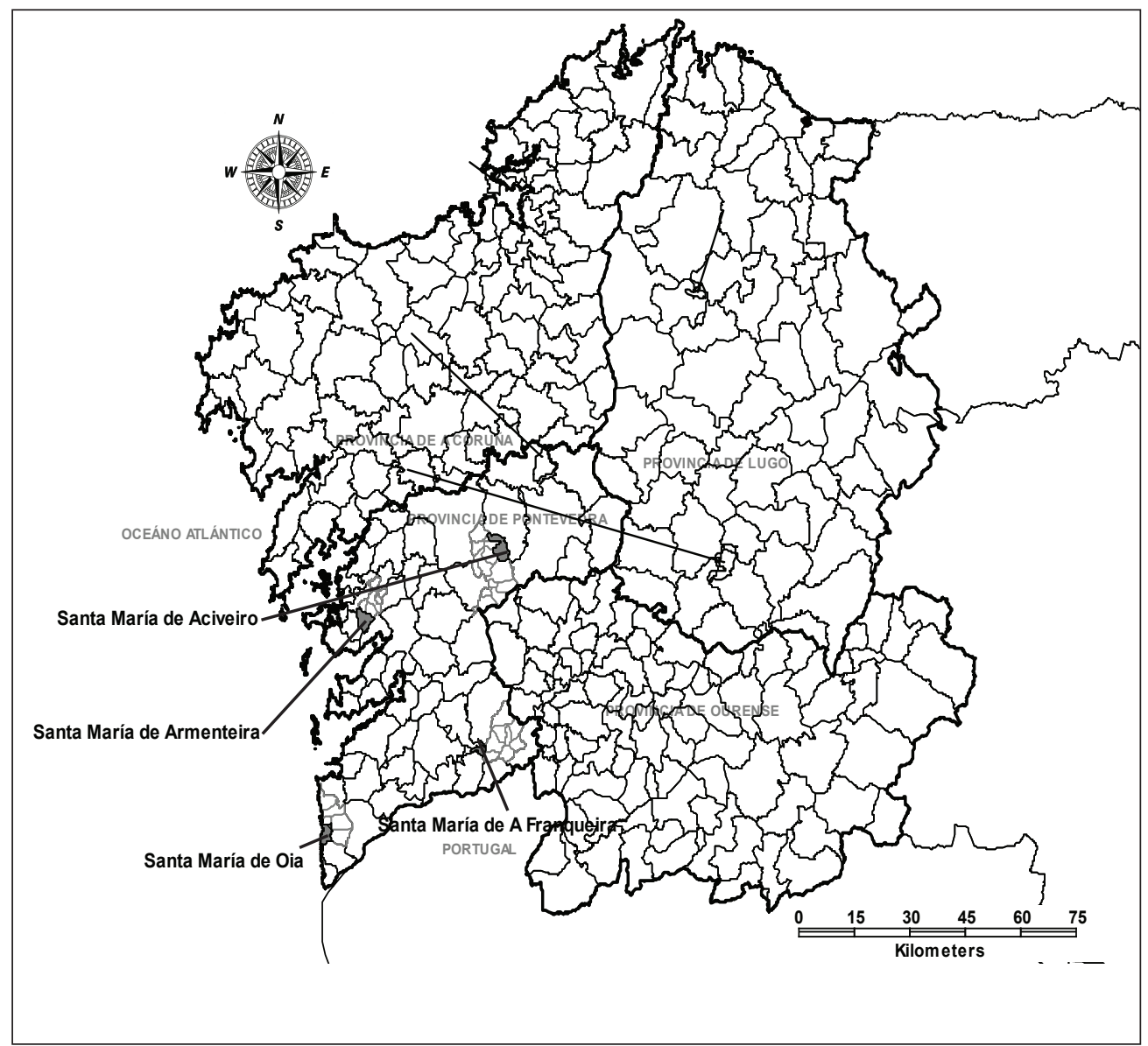

